\title{
SOLAR ENERGY, ITS CONVERSION AND UTILIZATION
}

\author{
By Dr. Erich A. Farber \\ Professor and Research Professor \\ Director, Solar Energy and Energy Conversion Laboratory \\ University of Florida \\ Gainesville, Florida
}

\section{Abstract}

This paper describes the work being carried out at the University of Florida Solar Energy and Energy Conversion Laboratory in converting solar energy, our only income, into other needed and useful forms of energy. A treatment such as this demonstrates, in proper perspective, how solar energy can benefit mankind with its many problems of shortages and pollution.

The paper will be conducted like a tour through the laboratory, describing the conversion processes, equipment, and performance. The testing of materials; solar water heating; space heating; cooking and baking; solar distillation; refrigeration and airconditioning; work with the solar furnace; conversion to mechanical power; hot air engines; solar-heated sewage digestion; conversion to electricity; and other devices will be discussed.

\section{Acknowledgments}

The Solar Energy and Energy Conversion Laboratory of the University of Florida was used as a basis for this paper, but credit must be given to the many laboratories around the world and individuals who are engaged in the effort to utilize solar energy for the betterment of mankind. Their work supports ours through ideas and results as our work is helpful to them.

Thanks must be given to the faculty, students, and staff of our laboratory who have, over the years, had an important part in advancing the state of the art of solar energy utilization. They have also provided knowledge and results for others to build on.

\section{Introduction}

The widespread concern with our energy situation and crisis, and what meeting the ever-increasing demand of this energy does to the environment through pollution, prompted the writing of this paper.
It presents the overall activities of the Solar Energy and Energy Conversion Laboratory of the University of Florida rather than the technical details of one particular investigation.

The laboratory has looked into old methods of converting solar energy into the forms of energy needed, has used the present state of the art, and has pioneered in many areas of solar energy utilization.

Before going into the various programs and efforts to utilize solar energy, the reasons for the great interest in this field should be presented.

It is obvious from all surveys and reports that we are using our fossil fuels at a tremendous and ever-increasing rate so that, in the not-too-distant future, these supplies of energy, so vital to our present growth of civilization, will be depleted. For this reason, it is of utmost importance that we look for other more permanent sources of energy and learn to use them before the dire need arises. Solar energy is readily available; well distributed; inexhaustible, for all practical purposes; and has no pollution effects upon the environment when converted and utilized.

Our present usage of energy can be compared to a family or group living off their savings, stored in a bank, and being steadily depleted. This process cannot go on very long unless some income is added to the savings.

In the field of energy the most abundant income is solar energy. This incoming energy was, usually in very inefficient processes and over millions of years, converted into our fossil fuels. With these savings rapidly disappearing, we will have to learn to use this income, in the form of radiant energy, directly, by converting it into the forms of energy needed.

This conversion from solar energy into the desired forms should be done in the fewest possible steps and along the most direct route. This procedure 
will insure the most efficient way of doing this and will keep the necessary equipment simplest.

Solar energy has certain characteristics. It is intermittent, only available during the day on a particular location on the surface of the earth. In spectral character, it approximates a blackbody source of about $10000^{\circ} \mathrm{F}$, modified by gaseous layers of both the sun and the earth's atmosphere.

It arrives on the surface of the earth both as direct radiation and diffuse radiation. The former portion can be concentrated if desirable.

A knowledge of the specific properties of materials under solar irradiation will then allow the collection and/or concentration and absorption of this energy.

If nighttime operation or operation during bad weather conditions is necessary or desirable, the storage has to be provided. For many applications, this is not necessary. The energy could be stored in a conventional manner as potential energy (pumped water, etc.) ; as heat in hot water storage tanks or rock bins; as chemical energy utilizing chemical processes, the latent heat or heat of fusion; etc.

In other words, the technology has been developed to convert and utilize solar energy, but the economics and sociologial acceptance has still to be worked out in many॰cases. These problems vary from region to region and therefore take on a local character to be worked out by the potential users.

To be most effective, local materials should be used in fabricating by local methods and labor fitting the economics and habits of the local civilization.

With this introduction of a general nature, the paper will now go into some of the work done by one group. The best way to do this is to take you on a tour through the Solar Energy Laboratory of the University of Florida.

\section{UF Solar Energy Laboratory}

The University of Florida Solar Energy Laboratory is one of the largest laboratories of this kind, and a tour through it will give an idea what such laboratories look like and the kind of work which is carried out in them. The work carried out at this laboratory is supported by work and persons all over the world, and proper credit should be given to them.

Figure 1 presents the entrance, within the gate to the laboratory, and two of the four buildings.

Stepping around these two buildings one can see some of the laboratory equipment, which will be discussed in more detail in the paper and the following illustrations. Figure 2 shows this equipment with engines of various types in the foreground and behind them are collectors and concentrators of various types. On the left of the picture are a small solar air-conditioning system and two solar water heaters, and a solar still and parabolic concentrators. Further visible are a solar power plant, a solar still, the solar furnace and solar calorimeter to investigate the solar properties of materials. In the background, partially visible, is a 5-ton solar airconditioning equipment.

\section{Solar Properties of Materials}

The first step in utilizing solar energy is to find materials which will withstand the exposure necessary in the equipment to be built. To do this, we take some of these materials and expose them under rather realistic operating conditions to the weather and the sun. Figure 3 shows different plastics exposed to the environment, stretched over cans which are filled with water or sand or wet soil, etc. If these materials deteriorate after a short time the investigation is terminated.

Those materials which, however, withstand this exposure test satisfactorily are then investigated in our Solar Calorimeter, as to their reflection, absorption, and transmission characteristics under actual solar irradiation (Fig. 4).

The Solar Calorimeter can be oriented into any desired position, it can be made to follow the sun, it can simulate severe winter conditions or extreme summer environments. It is further instrumented with many, many thermocouples to be able to obtain complete heat balances. This instrument, the only one of its kind, is constantly used to investigate new types of materials, such as glasses with tinting or coatings, laminated glasses and plastic materials, 
venetian blinds, thermopane windows, plastic bubbles for aircraft, fabric used for clothing, curtains and draperies, water-cooled venetian blinds, etc.

With the properties determined a selection can be made to obtain the best results in any desired application.

\section{Solar Water Heating}

In Figure 5, five different flat plate collectors used for water heating are presented. They consist of a box with glass or plastic covers (one or more) with a metallic absorber element inside, which contains the water. This water is circulated to the small water storage tanks shown above. These absorbers can be compared with each other when exposed to the sun under identical conditions and for the same length of time.

Some of the absorbers have copper plates with copper tubes soldered onto them; others are two flat plates riveted, crimped, or welded together. The most efficient unit found consisted of two thin flat copper plates fastened together on the edges and providing a water space of about 0.25 in., with one glass cover and 1 in. of Styrofoam insulation behind the plates. No plastic materials were found to be as good as glass since none of the ones we could find had the characteristics of glass - namely, letting through the short-wave radiation but not the longwave radiation. This characteristic of glass allows it to be used in the design of a solar trap.

Figure 6 presents a typical Florida Solar Water Heater. It consists of a sheet metal box, $4 \mathrm{ft}$ by $12 \mathrm{ft}$, covered by a layer of glass. Inside the box is a copper sheet with copper tubes soldered to it in sinusoidal configuration and connected to an 80-gal water storage tank. This system, rather common, is found satisfactory for a typical American family of four with an automatic washing machine, etc. Under the copper sheet is $1 \mathrm{in}$. of Styrofoam insulation. For satisfactory operation, the bottom of the hot water storage tank must be above the top of the absorber to provide circulation without a pump.

Figure 7 shows actual installations of this type in an apartment house in Florida with each apartment having its own unit to provide the needed hot water.
These standard units may be damaged if used in freezing temperatures, and for this reason, we developed a dual circulation system which eliminates this problem. It consists of two tanks, one inside the other, the outer tank being connected to the collector. This system is filled with an antifreeze solution. The heat is then transferred from this solution and through the wall of the inner tank to the water to be used. Since in this system the primary circuit operates at atmospheric conditions (the outer tank can just have a lid on it) the collector can be constructed much cheaper and lighter, for example, patterned after the most efficient design mentioned earlier. Insulation covers the outside tanks.

\section{Swimming Pool Heating}

Another type of heater which has interested many in Florida is a swimming pool heater, as shown in Figure 8. It is one of the simplest ones and least expensive. It consists of a galvanized sheet wrapped into plastic. The sheet is painted black (flat) like all the other absorbers. Water from the pool can be fed to these by the filter pump and then running down the front and back of the metal plate, drains back into the pool. It usually takes a collecting surface equal to the pool surface for raising the water temperature in the pool $2^{\circ} \mathrm{F}$. These absorbers can be constructed to form the fence around the pool, which is in many localities required by law, and, in addition, can provide privacy.

\section{House Heating}

If the objective is to heat a house rather than the water, it can be done by hot water circulated through baseboard pipes in a conventional hot-water heating system. However, frequently, it is more convenient or desirable to heat a building by hot air. Figure 9 shows such an air heater, made up of overlapping aluminum plates, painted black on the portion exposed to the sun. About one-third of each plate is showing; the other two-thirds is shaded by the plate above. They are put into a glass-covered box. The air will enter this unit on the bottom and then, streaming between the hot plates, will pick up the heat and leave on top as hot air. The circulation can be produced either by free or natural circulation or by a fan. 
All the above-mentioned collectors are ideally facing the south and inclined with the horizontal at an angle equal to the local geographic latitude, plus 10 deg. This gives a little higher collection efficiency during the winter when the days are shorter.

The air heater could be designed forming the wall of a building, let us say the east wall where it could produce hot air the first thing in the morning, to take the chill out of the building.

\section{Solar Cooking}

Another application can be a solar oven, essentially a glass-covered box facing into the sun. Cooking and baking temperatures can easily be reached with such a device (Fig. 10). Periodic (about every $15 \mathrm{~min}$ ) reorientation, because of the movement of the sun, is required. Flaps can be added (Fig. 11) to provide some degree of concentration and, thus, bringing the things to be cooked up to temperature quicker. Very little heat is actually required for the cooking process, only a certain temperature for the required length of time. If one of these ovens is to be used in the late afternoon or early evening, the walls could be made thick of clay or other materials which can store appreciable amounts of heat and thus remain warm long after the sun has gone down.

\section{Solar Distillation}

One of the major problems in many parts of the world is fresh water. With very simple equipment, solar energy can convert salt or brackish water into fresh and pure water. Figure 12 shows a simple solar still, a metal box with slanting glass facing south. Inside the box is a pan on short legs, painted black and holding the bad water. The sun shining into this pan heats the water and vaporizes it. The vapor or steam then will, when coming in contact with the cold surfaces of the box, both the glass and the metal, condense, forming the fresh water which runs down the sides in the form of droplets. This fresh water can then be collected for future use. About $0.5 \mathrm{lb}$ of water can be produced at an average per square foot, per day.

Another larger still is shown in Figure 13. The pan is covered by glass at about $45 \mathrm{deg}$, which forms most of the condensing surface. Glass is much better than plastic since it forms film condensation, letting the solar energy through without much difficulty. Plastics, in general, produce dropwise condensation, each droplet forming a little crystal which reflects much of the incident solar energy. This larger still is also designed to be able to collect rainwater and, in some areas such as Florida, this can double the output of the still.

The best orientation of the still depends somewhat upon the angles of the glass but is generally east-west or somewhat northeast-southwest.

\section{Solar Refrigeration and Air-Conditioning}

Another phase of our work is the use of solar energy for solar refrigeration and air-conditioning. At a number of international meetings it was pointed out that famine could be prevented in much of the world if the food, which is raised during certain parts of the year, could be preserved from spoilage, and thus preserved for use during the rest of the year. This requires refrigeration, and for remote areas, or areas without electricity, solar refrigeration may well be the answer.

Some of our early work along these lines was to heat oil to rather high temperatures by concentrating solar energy, and then circulating the hot oil around the generator of an ammonia absorption refrigeration system (Fig. 14). This picture is somewhat out of order since all the applications thus far dealt with solar energy in its natural state, without concentration, but it was put in here since it was actually our first attempt. We believe, however, that solar refrigeration without concentration holds much more promise since nonconcentrating devices can also utilize the diffuse portion of solar radiation, thus function even on cloudy days.

A number of small units have been built and then a 5-ton unit shown in Figure 15. Flat plate collectors heat water, which is then circulated to drive out the ammonia from the water in the generator of the system. This ammonia vapor is condensed and then expanded, providing the cooling effect by evaporation. After having done its work the ammonia vapor is reabsorbed in the ammonia absorber of the system into the water to repeat the cycle.

Figures 16 and 17 show a smaller version of such a system with some improvements. The main 
one, combining the solar collector and the ammonia generator into one unit, thus eliminates the primary fluid and reduces the heat losses by providing a more direct path for the solar heat to get into the system and do its work. On a good day this small 4 - by 4 -ft unit can produce $80 \mathrm{lb}$ of ice.

It should be pointed out again that all the applications mentioned so far did not require concentration of solar energy, and therefore could utilize the diffuse portion of solar energy and even work on cloudy days.

The solar air-conditioning or refrigeration systems have an added advantage, that the demand and supply are in phase. When the sun shines hottest, the need for refrigeration and airconditioning is greatest.

\section{Solar Energy Concentration}

For some uses, however, higher temperatures than can be obtained with flat plate, nonconcentrating collectors are needed. If this is the case, then concentration is called for. Many different methods can be used for concentration, the simplest ones stationary in design but not as good, and the better ones requiring methods which allow them to follow the sun.

Figure 18 shows a simple high-temperature absorber. It consists of a number of parabolic troughs oriented horizontally and with a pipe running down the focal line of the parabolas. The system of parabolic troughs is inclined at about the local latitude. Depending upon the diameter of the pipe, adjustment may or may not be needed during the year. The solar energy is reflected by the parabolic surfaces upon the focal pipe, which is painted with a good absorbing paint (flat black), absorbs this energy, and transmits it to the fluid inside the pipe. This device can easily produce hot water, steam, or hot oil.

Some energy is lost during the early morning and the late afternoon hours with the above method of converting solar energy to heat because of shading, but the simplicity and stationary design have considerable advantages economically and do not need much attention.

\section{Solar Power Plant}

If better efficiency is desired, then cylindrical parabolas, which are allowed to follow the sun, can be used. In the simplest form they can be made (Fig. 19) of a single parabola with a pipe at the focal line. This particular absorber is used to produce steam to operate a small steam engine, which in turn drives a small generator and lights up a light bulb, thus demonstrating what a solar power plant could look like. The 2- by $5-\mathrm{ft}$ absorber is the equivalent of 500 watts of electrical heat.

A large cylindrical parabolic absorber is shown in Figure 20, having dimensions of 6 by $8 \mathrm{ft}$, with a glass-covered focal tube. The glass cover reduces the losses from the heated tube. Depending upon the needs, different diameter tubes can be used. Copper has been found best, again painted with a good absorbing high-temperature paint. This absorber is mounted on a rotating axis parallel to the earth axis. It is adjusted to face the east in the morning and then, by an electrically driven worm gear reduction unit, is made to follow the sun all day. Where electricity is not available, a heavy weight with a clockwork timing unit can be used as well. The construction of such a large device must be rather rigid, since wind loads in windy areas may make it difficult to keep the unit directly facing the sun and to keep it from oscillating.

This unit has been used to produce steam for the operation of a fractional horsepower steam engine, to provide $800^{\circ} \mathrm{F}$ oil to operate a solar refrigerator, etc.

Other methods of concentrating solar energy are lenses both of glass and other materials (including liquid lenses), but they are not widely used because of their cost in large sizes and their weight. However, Fresnel lenses, specially made from plastic sheets, with grooves cut or embossed so as to focus the rays, can be produced rather inexpensively, are unbreakable and can be of large size and light weight. The lens shown in Figure 21 is of this type, and can produce temperatures of $2000^{\circ} \mathrm{F}$.

A very effective way of concentrating solar energy is to take flat pieces of reflecting materials (for better results, they can even be slightly curved), such as mirrors or reflecting metal surfaces, and oriented in such a manner as to reflect the solar radiation on one spot. Front surface reflecting mirrors are giving better performance than, for instance, back silvered mirrors, where some of the 
energy is absorbed in the glass. Very large concentrators of this type have been built with thousands of these mirrors used in some of the large solar furnaces in the world.

\section{Solar Cooking}

A few concentrating panels of this type are shown in Figure 22, where three of them concentrated upon a board will make this board flash into fire. Such mirrors can also be set up in a different pattern like the one shown in Figure 23 where the mirrors are set up into a circular pattern, heating the fluid in the jar at the focal region of the device.

If higher concentration, and thus, higher temperatures, and smaller focal regions are desired, then either smaller mirrors are needed or continuously curved surfaces can be employed. In this manner excellent concentrating mirrors, even of optical quality, can be made but they are very expensive, and there is a practical limit to the size of these configurations.

Two such mirrors of fair quality are shown in Figure 24, the one on the left being strong enough to hold its shape by being properly formed and the one on the right being supported by ribs from wood, in this case, which are cut out forming parabolas. Then thin, highly reflecting metal sheets are held loosely to these ribs to allow for expansion when the metal sheets are slightly heated, thus avoiding distortion. This type of construction is especially important in large sizes, and was also used in the large parabolic cylindrical concentrator mentioned earlier.

The two concentrators (Fig. 24) were used as solar cookers where only a moderate amount of concentration is needed (too good a concentrator may burn holes into the containers used if great care is not taken). Therefore, not too good a quality is more desirable for this application.

If such concentrators are used for solar cooking, it may be desirable to design them for easy portability, thus either in sections which can be collapsed for moving, or of coated cloths of an umbrella design which can be folded when not in use. This type of an oven and a cooker of moderate concentration is shown in Figure 25. The flaps on the oven can be adjusted to regulate the degree of concentration needed. An oven of this design will shorten the cooking and baking time by bringing the food up to the desired temperature faster than the type mentioned earlier.
Higher concentration, that is, higher concentration than the surfaces previously discussed can provide, is needed for high-temperature work, solar engines, etc. For this purpose, the geometry has to be more perfect. Figure 26 shows various mirrors of rather high quality giving high degrees of concentration, with the ultimate reached in the solar furnace (Fig. 27).

\section{Solar Furnace}

This solar furnance, with a 5-ft-diam mirror, can produce concentration ratios of almost 25000 and temperatures of up to $7000^{\circ} \mathrm{F}$.

Solar furnaces can be used for research where high temperatures and extremely pure, uncontaminated heat are needed. Materials can be enclosed in glass containers or plastic containers, surrounded by vacuum or any desired atmosphere, and heated under very closely controlled conditions. Since the solar energy can be concentrated onto a very small region, it is not necessary for the support of the sample to be able to withstand very high temperatures, nor is it necessary for the glass or plastic container to be high-temperature resistant since the energy, as it goes through this material, is not yet concentrated to a high degree (Figs. 28 and 29).

The furnace has been used to produce extremely high purity materials, to grow crystals of hightemperature materials - crystals nonexisting in nature, to extract water from rocks and moisturecontaining soils (work which may be of great importance when a lunar station is going to be set up, since many experts believe that the solar furnace will be an important tool on the moon), and it may be possible to produce materials on location instead of hauling them from the earth to the moon. We received a citation from the Air Force for this work.

\section{Mechanical Power}

One of the largest programs in our laboratory is the conversion of solar energy into mechanical power. This is done by steam engines, one of them shown in Figure 30 and supplied with steam from the large cylindrical parabolic concentrator (Fig. 31). The combination shown will give about 0.25 horsepower, only limited by the concentrator and quantity of steam delivered by it.

A working model of a steam power plant is shown in Figure 32, with the absorber and boiler shown from the front (Fig. 18), and the engine driving a generator 
and lighting up a small light bulb. A steam engine with a different type of absorber is also shown in Figure 33. The small square boiler in this case must be used with the concentrators shown in Figure 22 . Other combinations and designs are possible and will work equally well, if designed properly.

We believe, however, that hot-air engines have a much greater promise than steam engines for fractional horsepower requirements. They are safer, quiet, and only need a source of heat, any source. These engines can be operated off solar energy during the day and, if power is needed during the night, by other sources of heat, such as wood, coal, oil, or it can be operated by the heat produced from the burning of waste products such as trash, cow dung, etc.

\section{Closed-Cycle Hot Air Engines}

There are two basic types of hot-air engines. One is the closed-cycle type, which encloses a certain a mount of air which can be pushed back and forth by a plunger between hot and cold surfaces. When the air is in contact with the hot surfaces, it is heated and thus increases the pressure in the engine. When in contact with the cold surfaces, it is cooled, thus decreasing the pressure in the engine. A power piston is pushed down when the pressure in the engine is high and returns because of flywheel action when the pressure is low. So every downstroke is a power stroke. With proper timing of the power piston and the plunger, considerable amounts of energy can be produced.

These engines are inherently slow-speed engines, a few hundred revolutions per minute, since it takes time to heat and cool the air. The heat transfer can be improved by either pressurizing the engine or filling it with gases, such as hydrogen or helium. Also, a large surface regenerator will increase the performance of such engines, but they become more complicated and much more expensive by such additions and refinements.

Figure 34 shows a quarter-horsepower engine with the displacement cylinder in a horizontal position on top and the power cylinder directly underneath in a vertical position. The blackened end of the displacement cylinder is heated and the other end cooled, in this case, by a water jacket. Figure 35 shows such an engine disassembled. The basic unit for this engine is a lawnmower engine, but the engine itself is much simpler and less expensive since it does not require any valves, carburetor, or electrical system.

Another engine (Fig. 36) is shown in operation with a radiation shield around the hot end of the displacement cylinder. The concentrated solar energy can clearly be seen heating the end of the displacement cylinder. A 5-ft mirror is used with this engine, which has to be moved about every $15 \mathrm{~min}$ to keep the energy concentrated on the engine. This movement is rather small and could be automated. Enough heat capacity is built into this engine so that if small clouds pass over the sun the engine will continue to operate.

These engines are not self-starting and after the engine surfaces are heated they must be given a push but will then take off on their own. This should be no handicap if compared with the attention a team of bull oxen requires. A single man can operate a bank of these small engines, adjusting the mirrors periodically. In addition, no further land is needed, as in the case when animals are used to raise the food they need.

Figure 37 shows another one of the closed-cycle hot air engines in operation. In Figure 38 it is pumping water out of a ditch. The mirror shown with this engine is actually much better than needed but was used since it is available. It is an old mirror from the solar furnace which has been polished so many times that the reflecting surface is no longer very good. For engine operation the concentrator only has to be good enough to provide a spot of concentration of the size of the displacement cylinder of the engine, about 3.5-in. diam, for the engine shown.

A one-half horsepower engine, closed cycle, is shown in Figure 39, which is designed to be used with solar energy and can directly, without modification, be used to burn wood, coal, or liquid fuels. If used with solar energy it is only necessary to open the big door shown and to concentrate the solar energy upon the end of the displacer cylinder inside the furnace box.

\section{Open-Cycle Hot Air Engines}

The other type of hot air engines is of the opencycle type (Fig. 40), which takes atmospheric air, compresses it, then heats it, again by solar energy or other means, expands the air and exhausts it into the open. 
These engines have the advantage that the heating of the air and the speed of the engine are independent, therefore these engines can be made to run at much higher speed. This higher speed makes it possible to reduce the weight per unit power output, but the engines built by us so far do not have as high a conversion efficiency as the closed-cycle engines.

Both these types of hot air engines, but especially the closed-cycle type, can be built without special equipment and with only the simplest types of machine tools. The timing for best performance is rather critical and should be adjusted carefully. Another critical parameter of the closed-cycle engine is the clearance volume.

Our work was concentrated on fractional horsepower engines of the portable type which could be used for irrigation or drive s mall machinery.

There are other solar devices which can convert solar energy into mechanical energy but they are of less importance.

\section{Solar Pump}

Figure 41 shows a solar pump model, in this case, made out of glass so that its operation can be observed. It only has two check valves and otherwise, no moving parts. A boiler is connected by a straight and a U-shaped tube to a chamber with check valves at the inlet and outlet. The liquid in the boiler is vaporized, pushing liquid out of the system, and when the vapor reaches the bottom of the U-tube, it suddenly streams into the other chamber filled with cold liquid, where the steam rapidly condenses. While the stream is produced, the top check valve is open and liquid is pushed out. When the vapor condenses the top check valve closes, because of the vacuum produced, and the bottom check valve opens, letting in more new liquid to be transported. This pulsating action can be smoothed into a steady flow if an air chamber is provided past the top check valve.

\section{Solar Turbine}

Another method of converting solar energy into mechanical energy is by means of a turbine, a model of which is shown in Figure 42. A vertical chamber with a turbine wheel in it is filled with a volatile liquid to just above the turbine wheel. The collecting surface has a cover with a small hole in the bottom of the chamber. The liquid will drain through this hole into the space below, will come in contact with the hot surface below and vaporize. The vapor will stream upward forming a jet which in turn drives the turbine wheel. When leaving the turbine wheel it will come in contact with the cold surfaces of the upper part of the vertical chamber and condense, running down the walls and repeating the cycle.

For some applications it is more convenient to separate the steam generator from the turbine and the condenser.

\section{Solar-Gravity Motor}

Shifting of weights from one side to the other on a wheel or seesaw can do work. Figure 43 shows a motor where a number of spheres, two at a time, are connected by a tube and mounted on a wheel. The sun shining on one side will vaporize the liquid, and the vapor streaming to the other side will condense. If properly designed, continuous motion can be obtained, which can be used to pump water or do other useful work. The conversion efficiency and power output are rather small but may be sufficient for certain tasks.

\section{Solar Thermo-Phase Shift Reciprocating Engine}

Figure 44 shows another device for the conversion of solar energy into mechanical energy. It consists essentially of a column of water with bellows at the top. The system is completely purged of air. The end of the tube is heated by concentrating solar energy upon it or any other concentrated source of heat. This will vaporize the water on the end of the tube and force the column of water to the right, as shown in the picture. With vapor now in contact with the hot surface, the heat transfer is suddenly decreased tremendously, and so, the cooling effects are now greater than the heating. The vapor condenses, letting the column of water return to the left until it touches the hot end, and the cycle repeats. Cooling of the lower end of the column of water will improve the performance. The moving column will make the end of the bellows move back and forth. By coupling to a flywheel, this reciprocating motion may be transformed into rotary motion. This very simple little device is quite noisy, sounding like a small gasoline engine and can, by adjusting the pressure on the end of the bellows, be made to run at 
different speeds, several hundred cycles per minute if desired.

\section{Conversion to Electricity}

If electricity is desired as the form of energy to be used, it can be produced by converting solar energy into mechanical energy and then driving a conventional electric generator. The solar energy can be converted more conveniently directly into electricity by one of the many solid-state devices, normally referred to as solar cells. Through the space program great strides have been made in the photogalvanic conversion field utilizing silicon as the most common material. Two photogalvanic converters are shown in Figures 45 and 46.

Thermoelectric conversion has also been investigated in our laboratory, using certain semiconductor materials as superthermocouples as well as thermionic conversion, but not a great deal of energy was spent in these areas.

\section{Sewage Treatment}

Another project of interest is application of solar energy to sewage treatment. One phase of this work provided solar heating for sewage digesters. By heating these digesters and controlling the temperature for optimum efficiency, considerably more sewage can be handled by a given size plant. Many plants buy expensive covers ( $\$ 30000$ and more for not a very big one) and collect the sewage gas and then burn it to heat the fluid in the digesters. Many of these plants even buy fuel, and all of this becomes a very expensive operation. Solar heating of these digesters proved relatively inexpensive by being able to use plastic sheets glued together to form an airmattress-type cover floated on top of the digester. This, in many cases, provided enough of a solar trap to keep the digester at good operating temperatures in our region. As a matter of fact, in one winter with rather severe and prolonged freezes, all the bacteria in the unheated digesters died and action stopped completely until they were restocked. During this same period the solar-heated digesters survived, and the bacterial action, even though slowed down during the extreme cold spells, picked right up again when the temperature of the digesters increased. The basic problem of heating here is the same as for swimming pools (Fig. 47).

If the digester is designed more like a solar still, in addition to the digestion, fresh water can be produced by distillation and the remaining sludge used for fertilization.

\section{Conclusion}

The above discussion is provided with a number of illustrations because we believe that pictures can tell a story much better, covers much of our work, but by no means all of it. It presents the range of activities in our laboratory.

When solar energy utilization is contemplated, its availability and amount of supply, the requirements, the availability of materials and labor, as well as economic considerations should be analyzed on a regional or local basis, since la rge variations can occur from place to place on a global scale. The devices discussed and shown here may have different degrees of applicability in different areas.

We recommended one time, as an example, for an Army post in Chile to spread steel pipes on the sandy ground and to hook them together into a number of parallel circuits to provide the hot water they needed; they had the steel pipe, the labor and the sandy land. To recommend the Floridatype solar water heater would have been the wrong thing to do since they did not have copper sheets, copper pipes, and hot water storage tanks. Their problem was solved with local materials under local conditions and produced the required results.

In closing, I would like to say that solar energy, its conversion and utilization, will not solve all our problems, but it will be a great step in the right direction, by supplying needed energy wherever it can without having adverse effects upon the environment and, at the same time, conserving our fossil fuels, which can do much more for us than provide heat. The chemicals they contain can be used as preservatives, in medication, etc., so that the indiscriminate use of these resources for energy is unwise and a loss to future generations. 


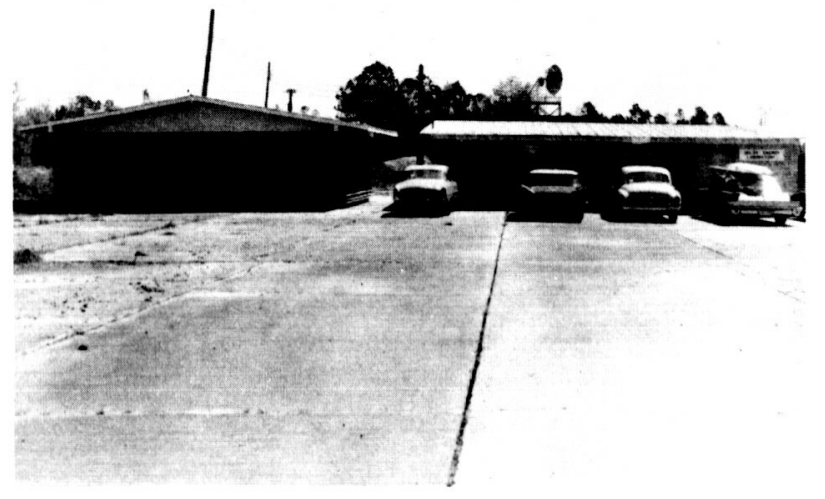

Figure 1. Entrance to University of Florida Solar Energy Laboratory.

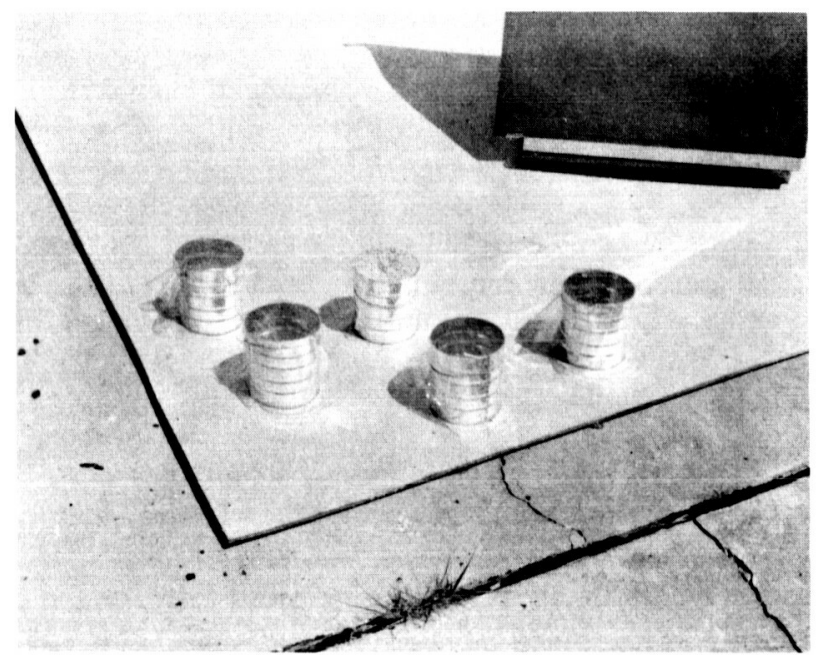

Figure 3. Exposure test of some plastic films.

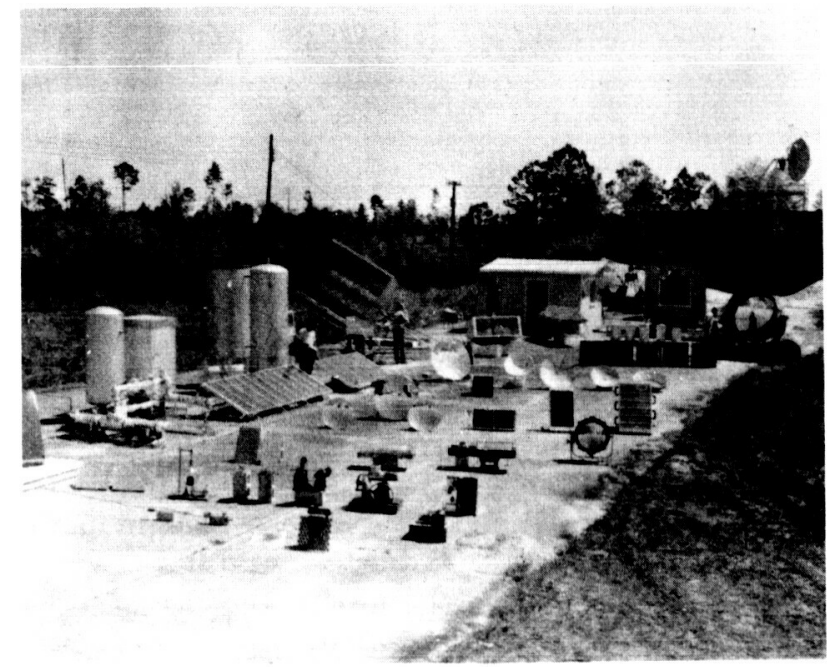

Figure 2. View of some of the solar energy conversion equipment in the laboratory.

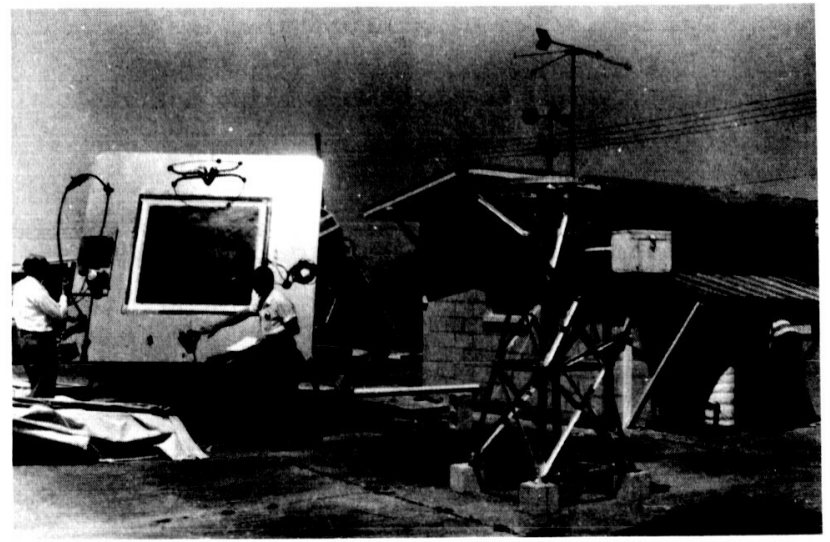

Figure 4. Solar Calorimeter. 


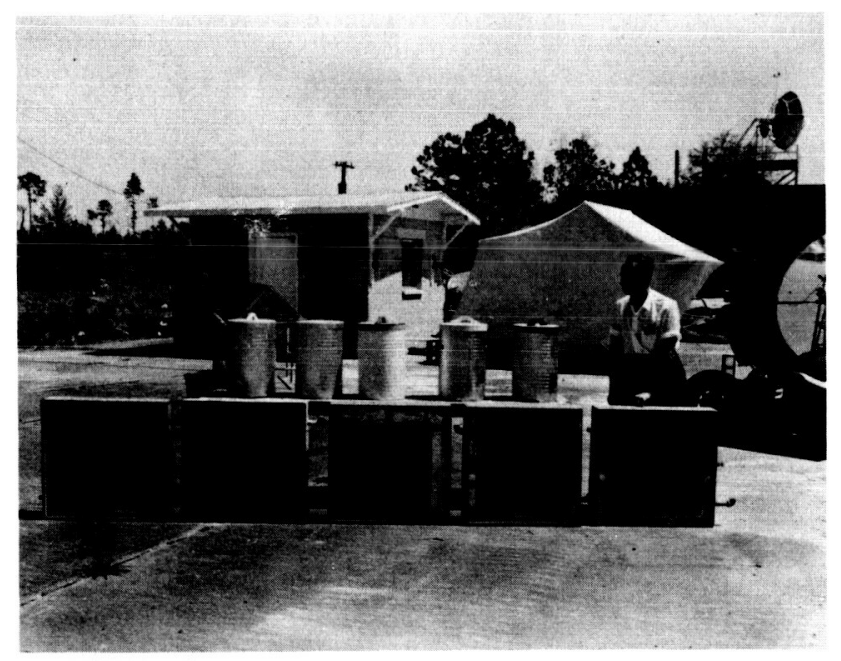

Figure 5. Experimental flat plate collectors.

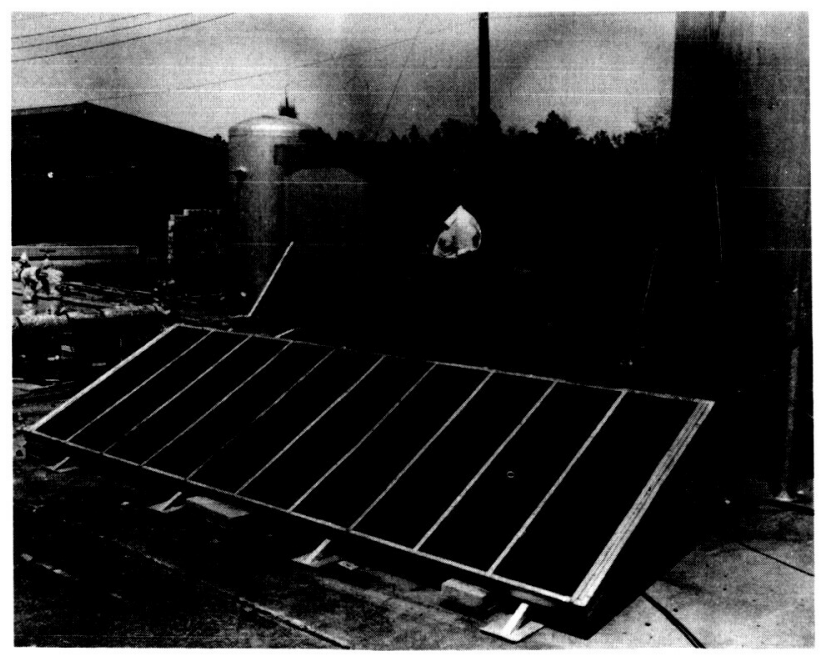

Figure 6. Florida-type solar water heater.

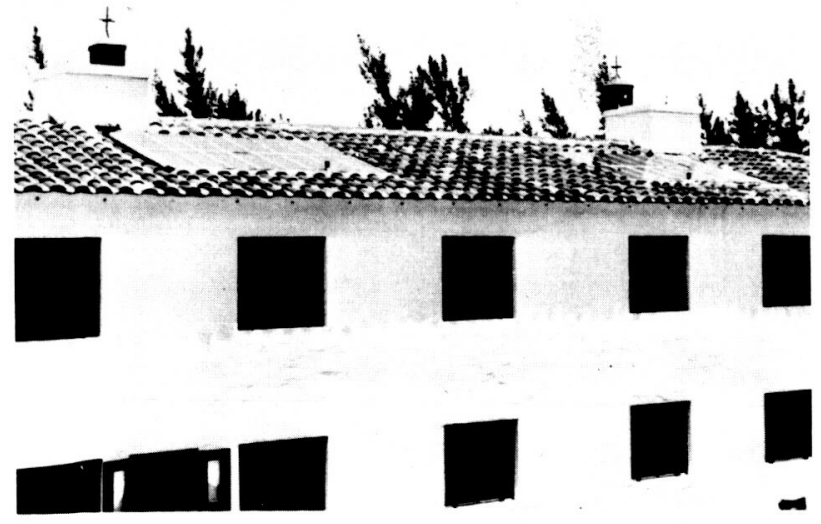

Figure 7. Solar water heaters in an apartment house. 


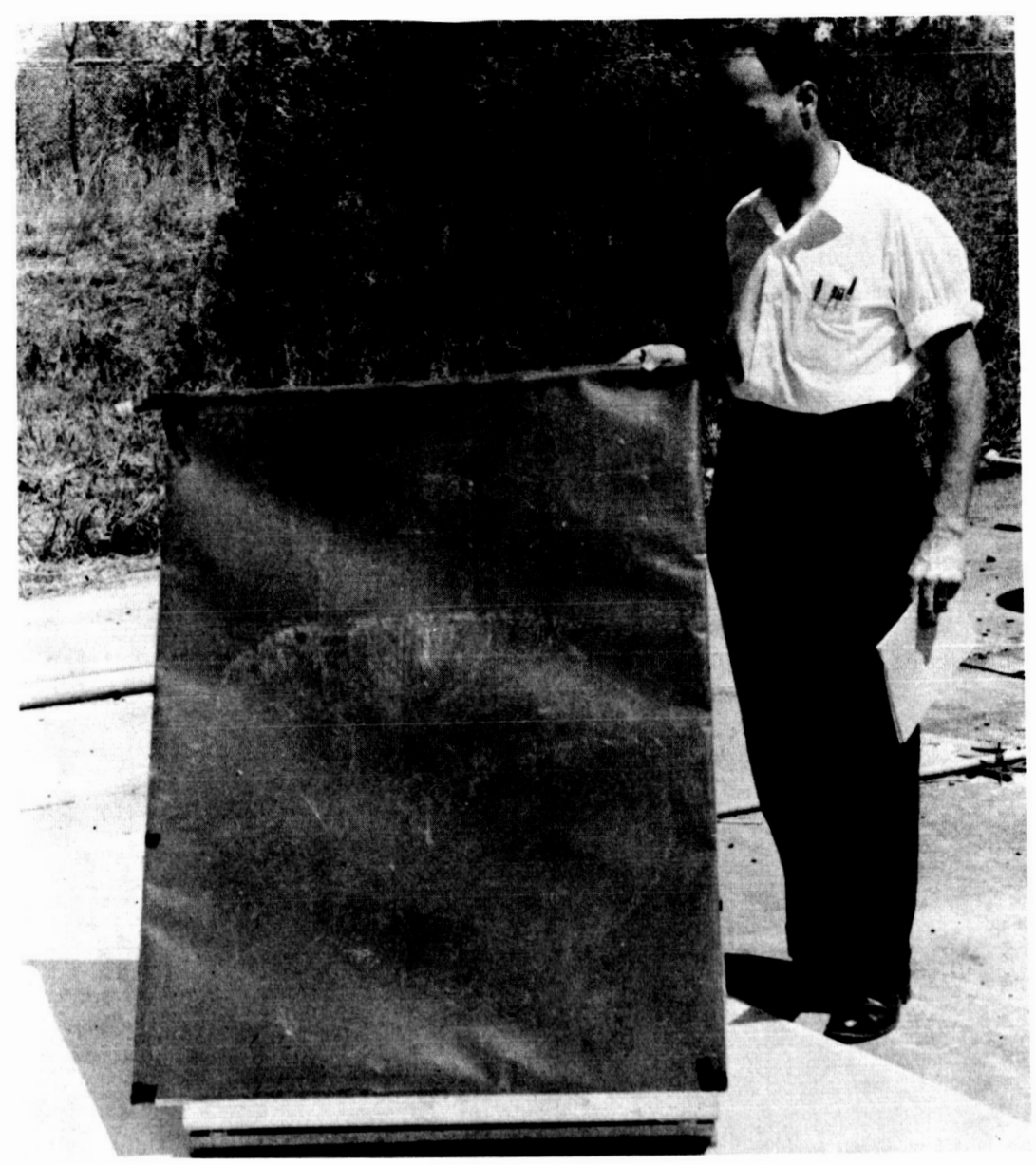

Figure 8. Swimming pool solar heater.

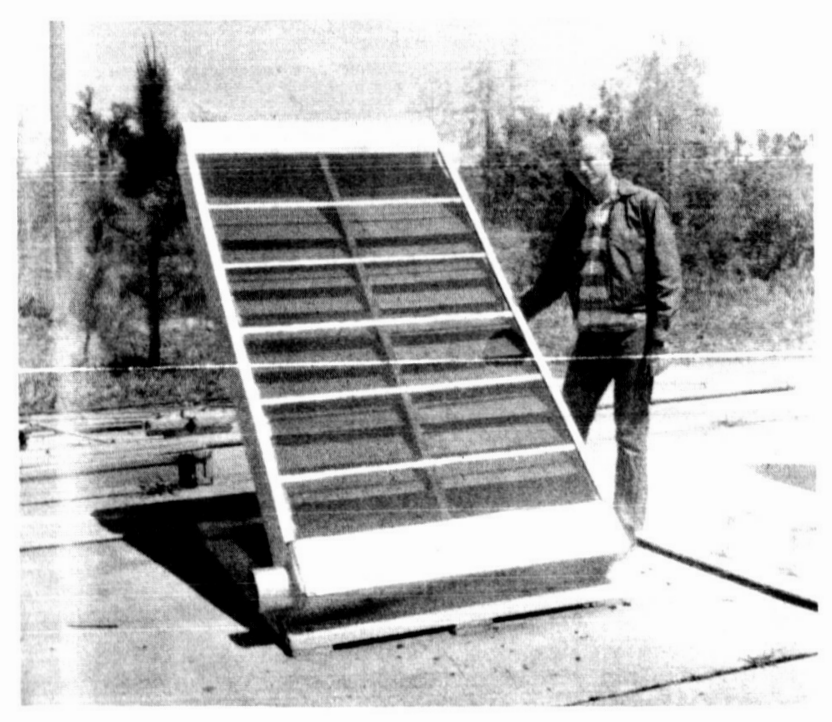

Figure 9. Solar air heater.

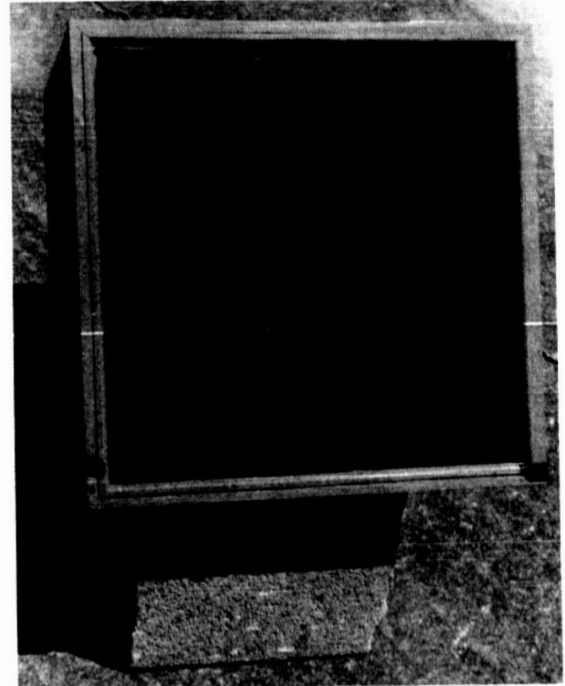

Figure 10. Solar oven. 


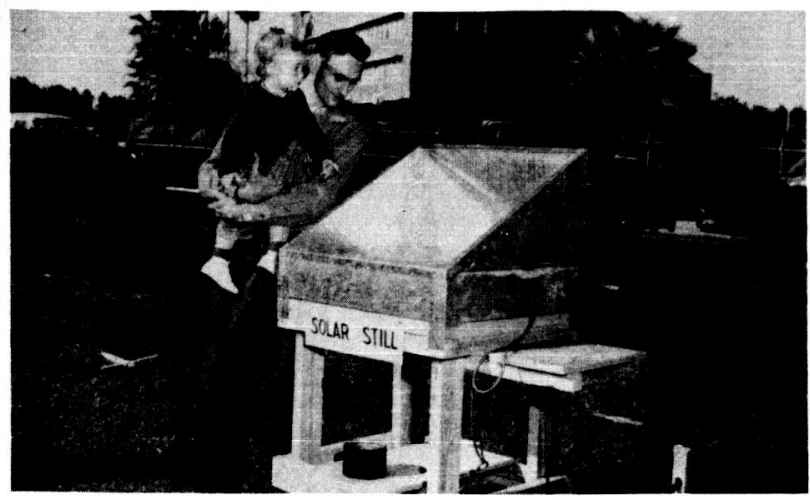

Figure 11. Small solar still.

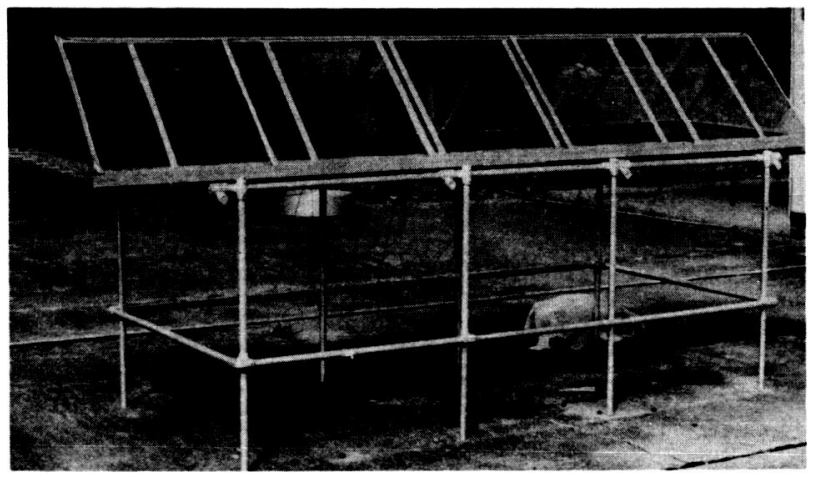

Figure 12. Larger solar still, also able to collect rainwater.

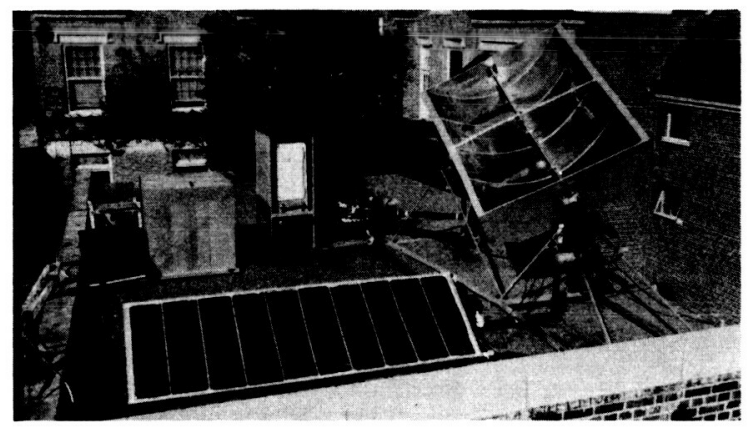

Figure 13. Refrigerator driven by solar energy.

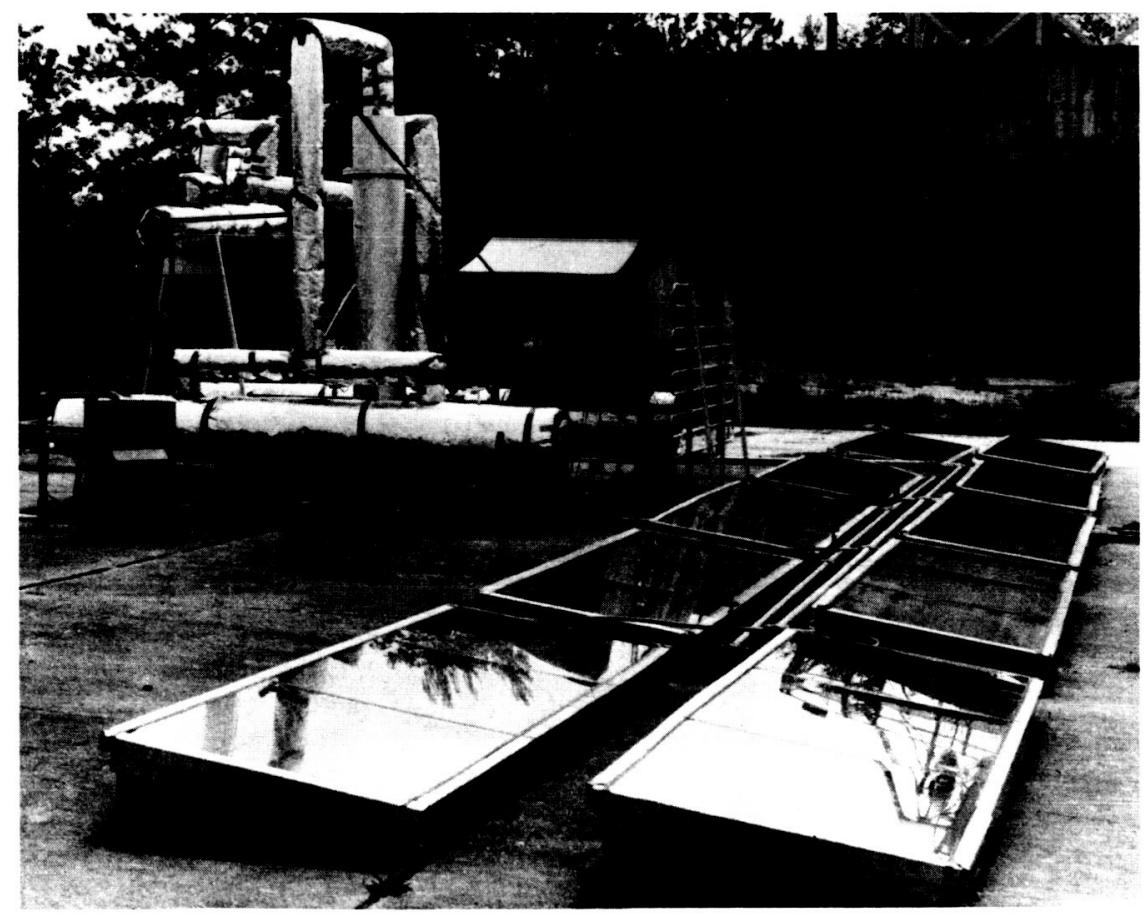

Figure 14. Five-ton solar air-conditioning system. 


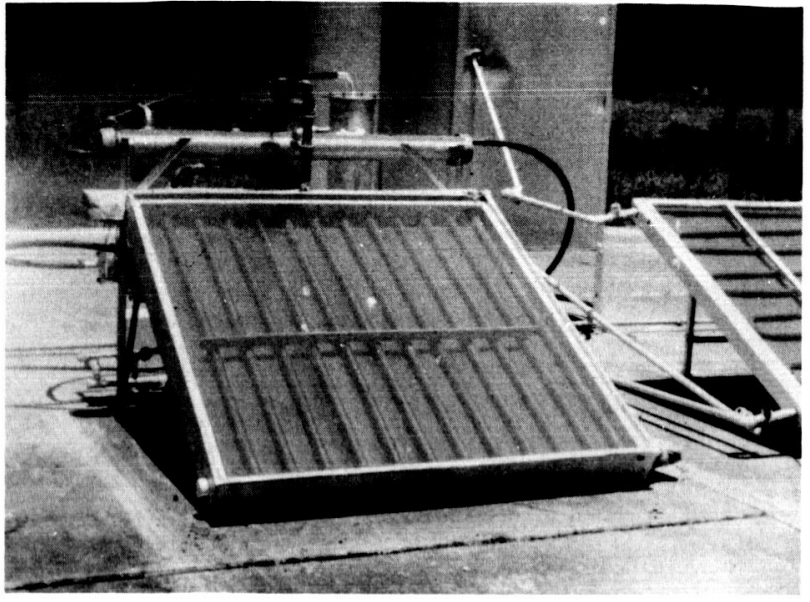

Figure 15. Small solar refrigeration system, front.

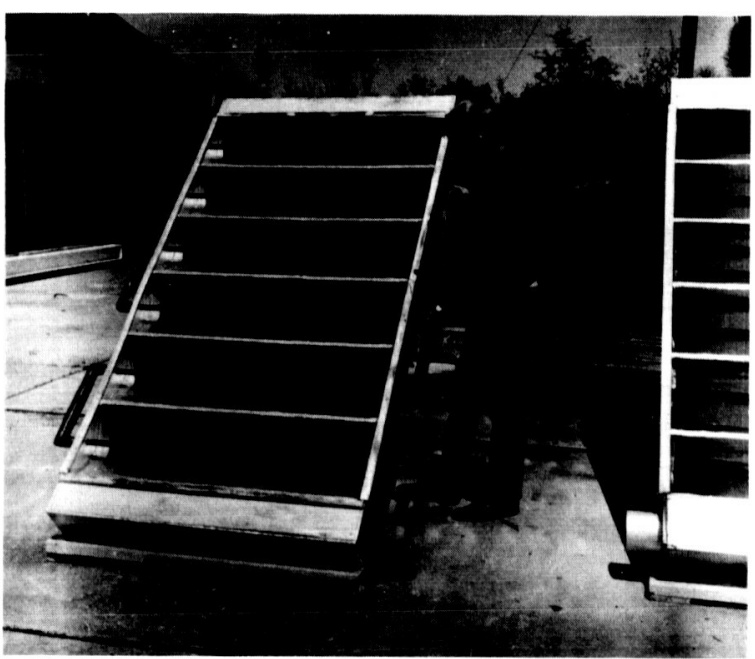

Figure 17. Stationary high-temperature absorber.

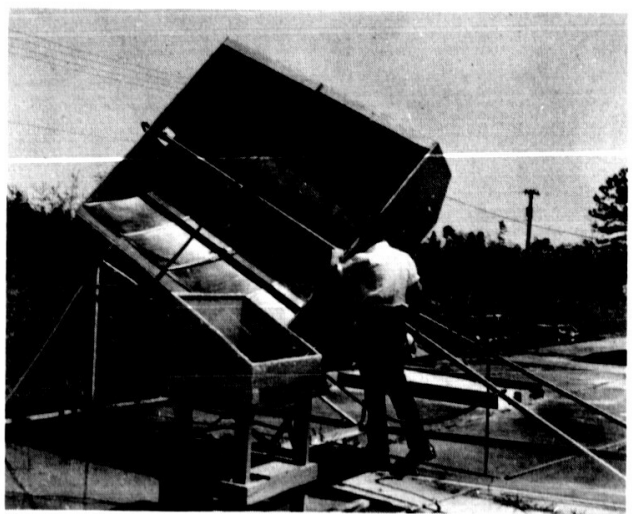

Figure 19. Cylindrical parabolic absorber, 6 by $8 \mathrm{ft}$.

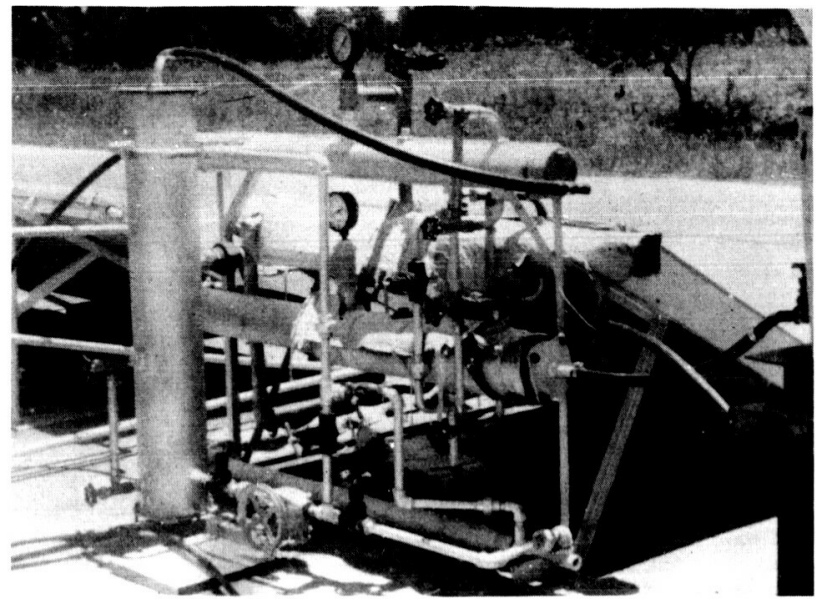

Figure 16. Small solar refrigeration system, back.

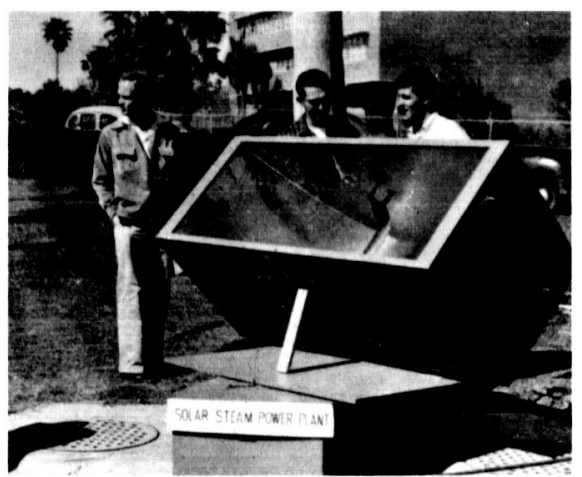

Figure 18. Solar steam boiler of solar steam power plant.

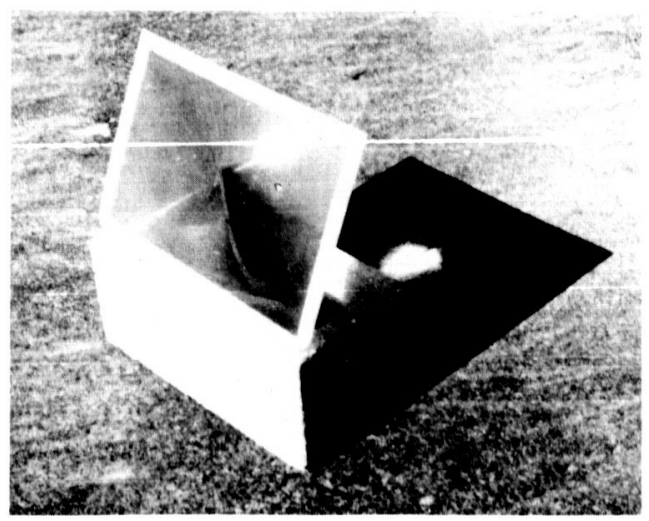

Figure 20. Plastic Fresnel lens. 


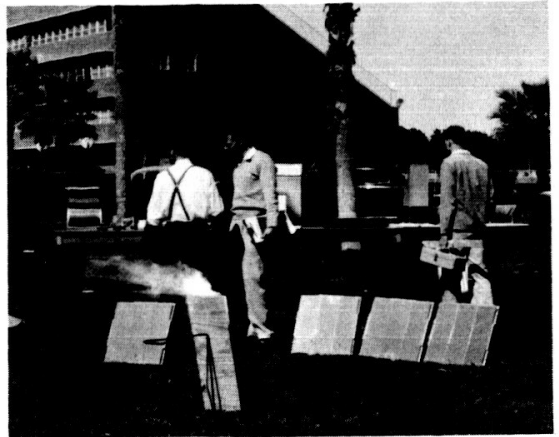

Figure 21. Solar concentrating panels.

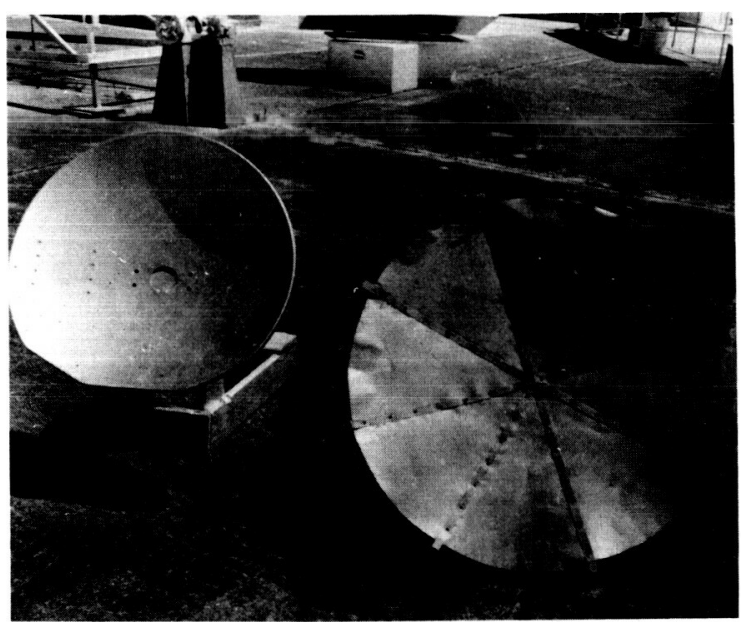

Figure 23. Parabolic solar concentrators.

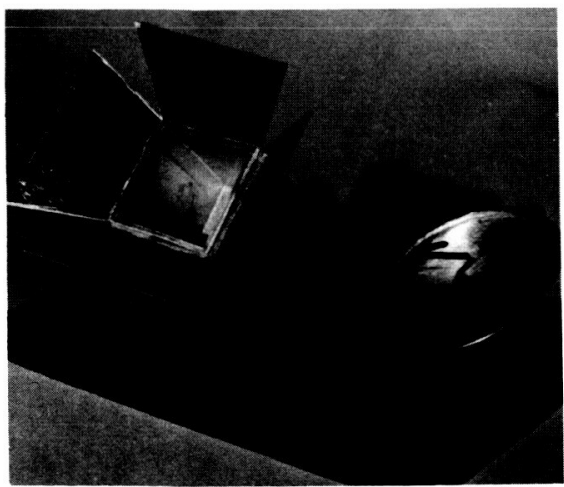

Figure 25. Solar oven and solar cooker.

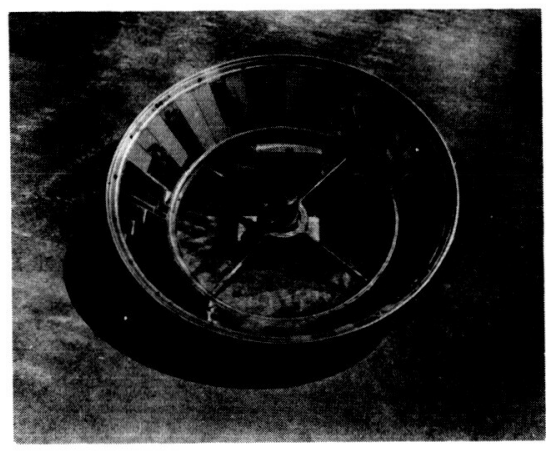

Figure 22. Solar cooker.

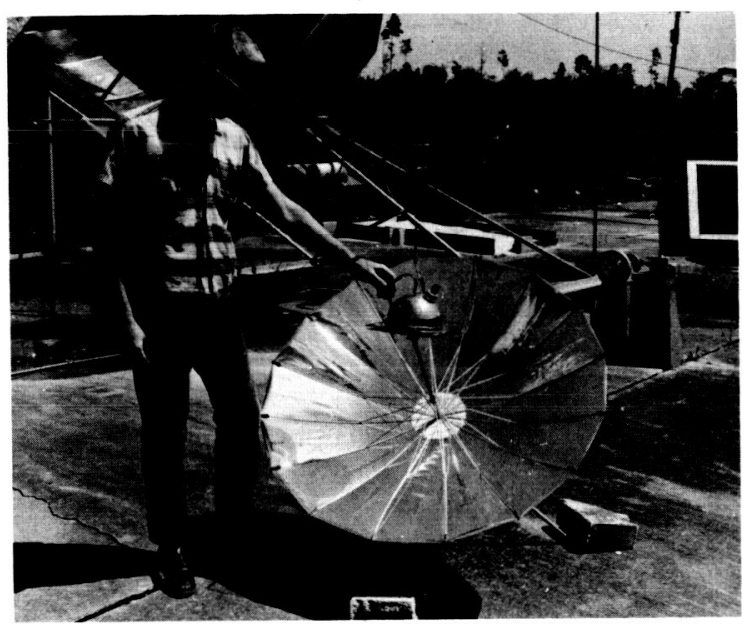

Figure 24. Collapsible solar cooker.

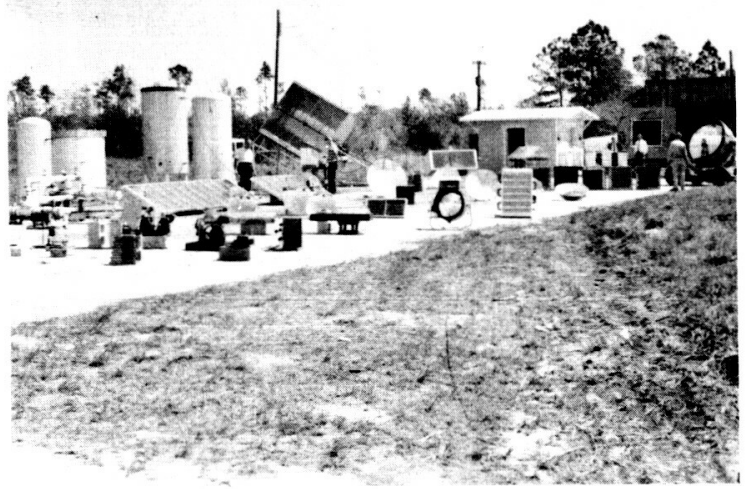

Figure 26. Concentrating mirrors. 


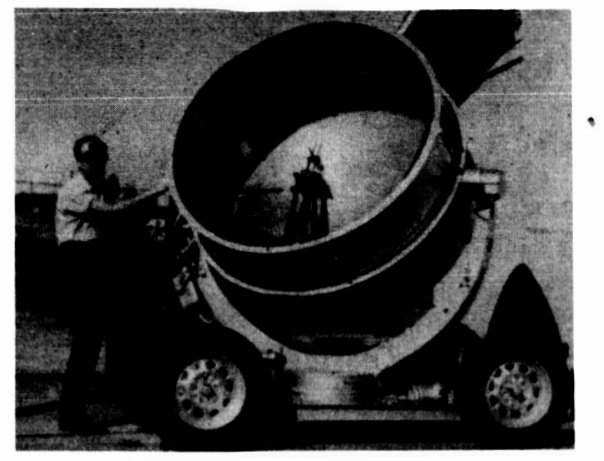

Figure 27. Five-foot solar furnace.

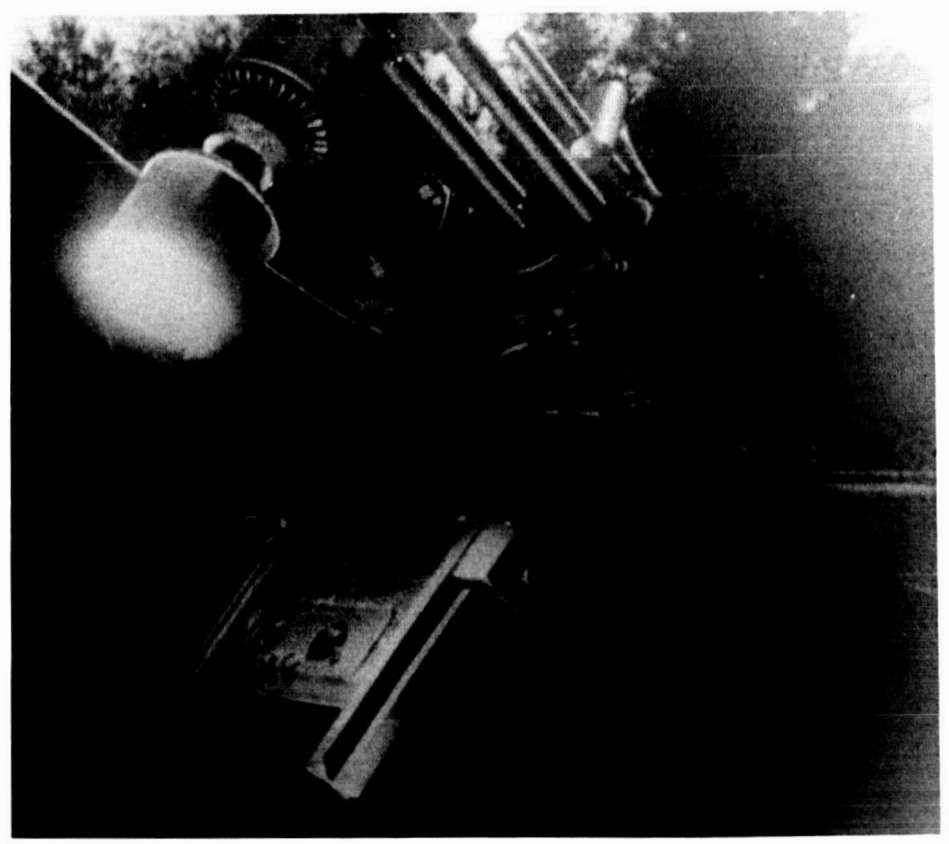

Figure 28. Concentrating solar energy.

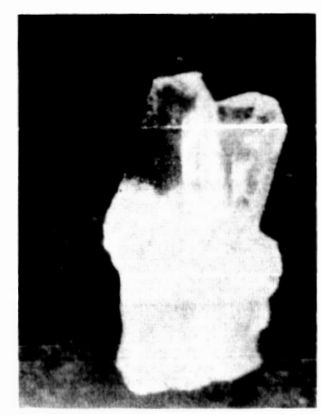

Figure 29. High-temperature crystal growth from the solar furnace.

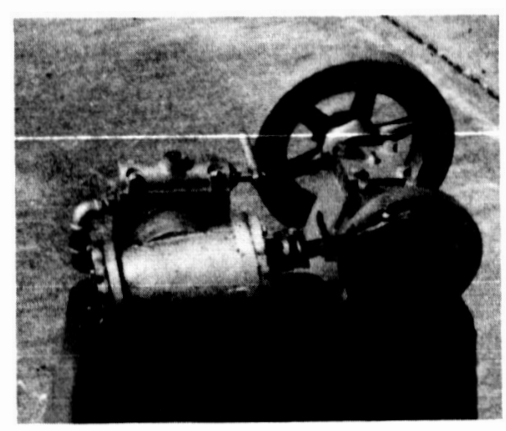

Figure 30 . Small steam engine. 


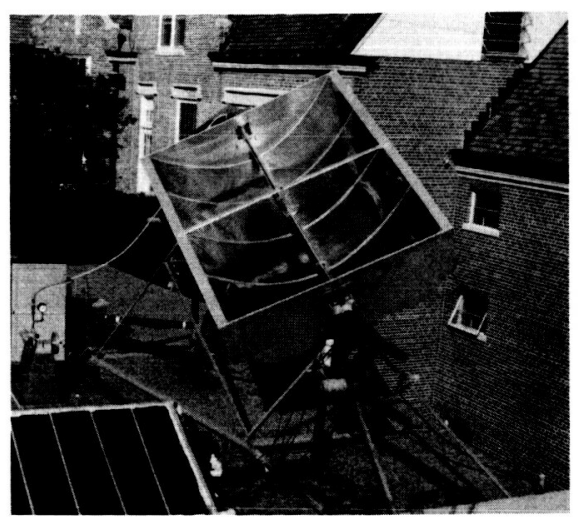

Figure 31. Steam engine operated by solar energy (one-fourth horsepower).

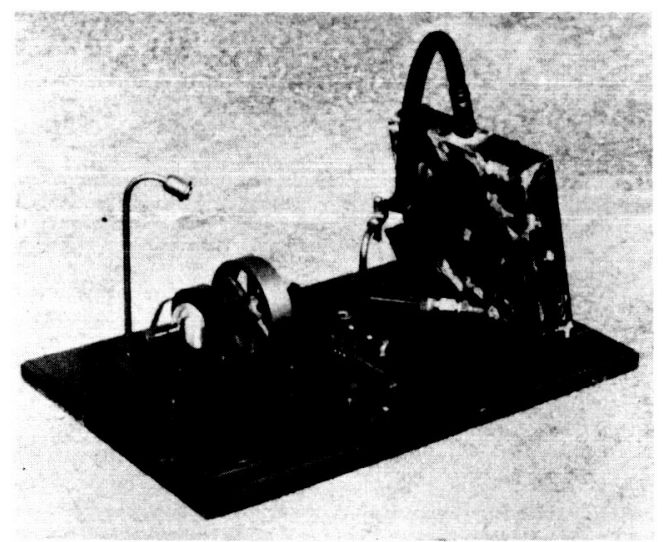

Figure 33. Solar steam power plant (see also Figure 21).

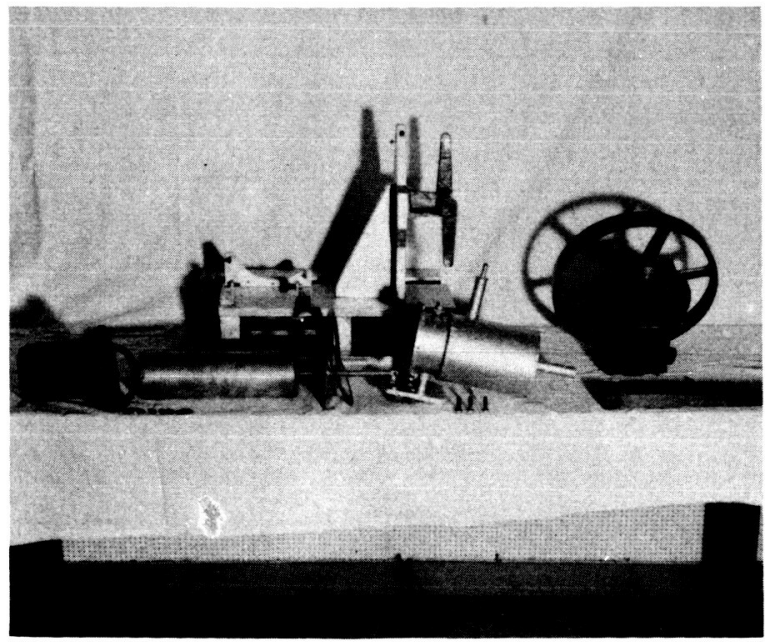

Figure 35. Disassembled, closed-cycle hot air engine.

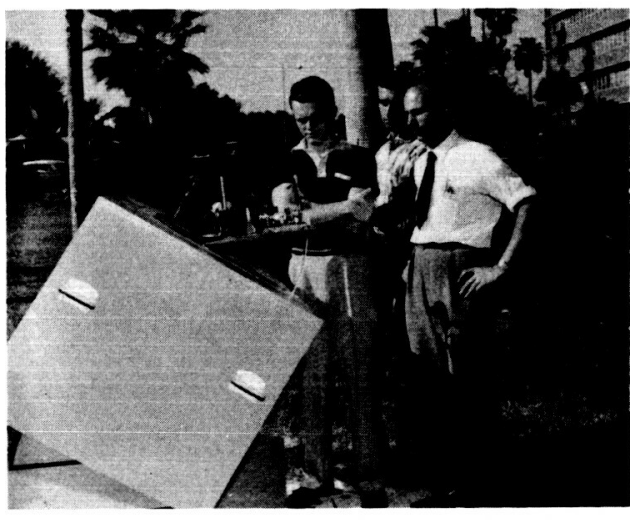

Figure 32. Solar steam power plant ( see also Figure 17).

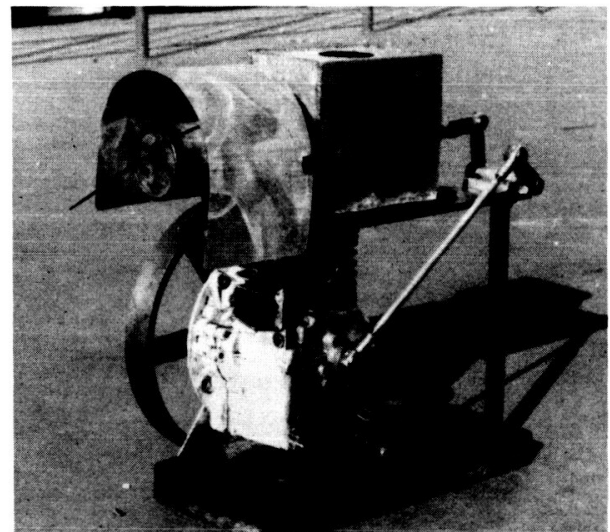

Figure 34. Closed-cycle, hot air engine one-fourth horsepower.

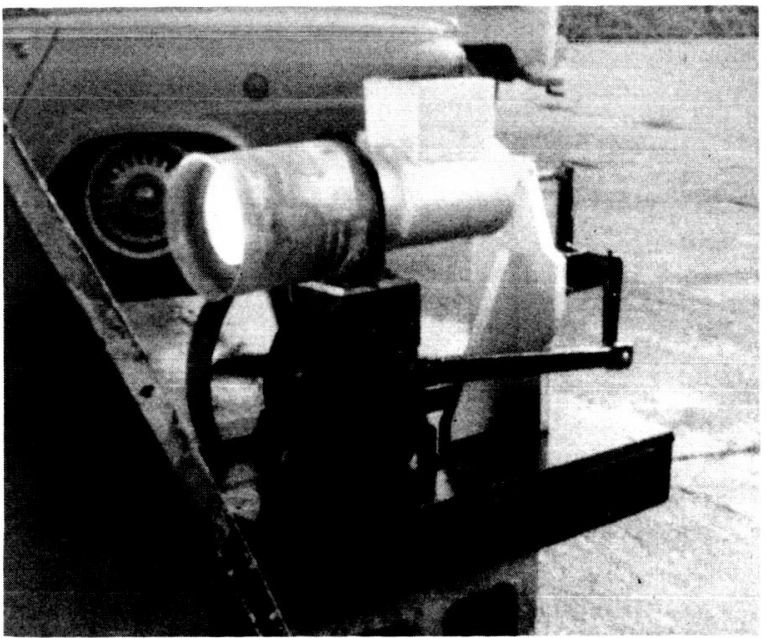

Figure 36. Hot air engine operated by solar energy. 


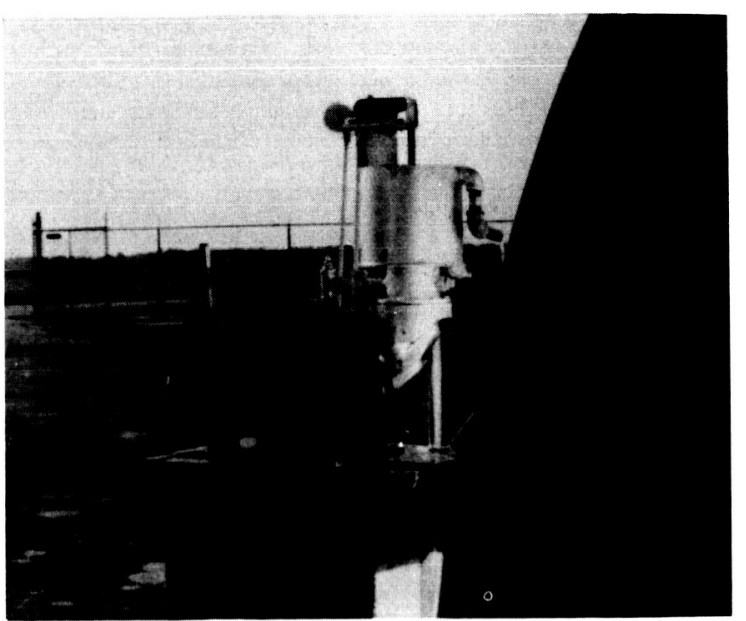

Figure 37. Closed-cycle, hot air engine.

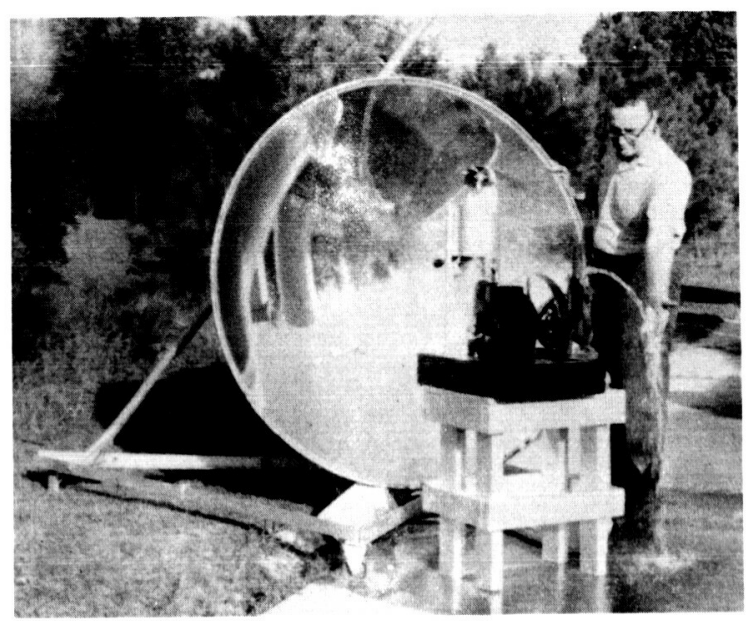

Figure 38. Pumping water with solar energy.

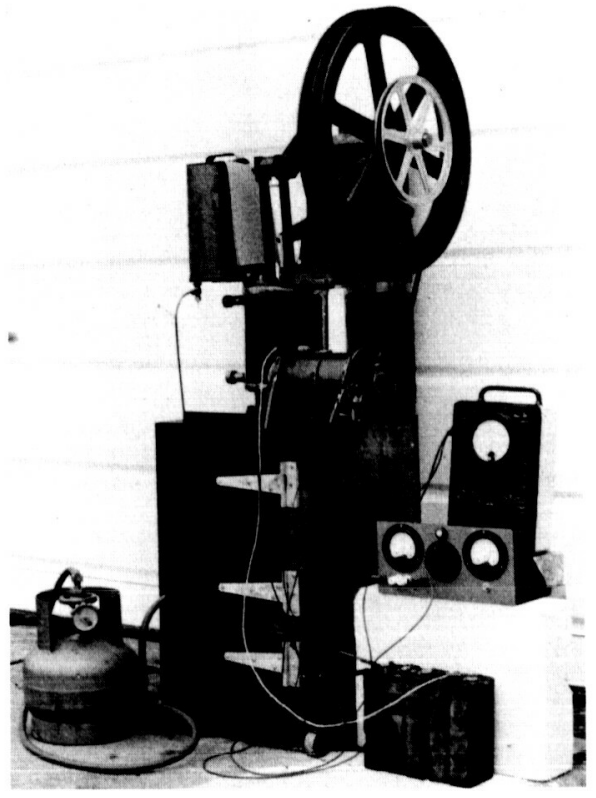

Figure 39. Closed-cycle, hot air engine.

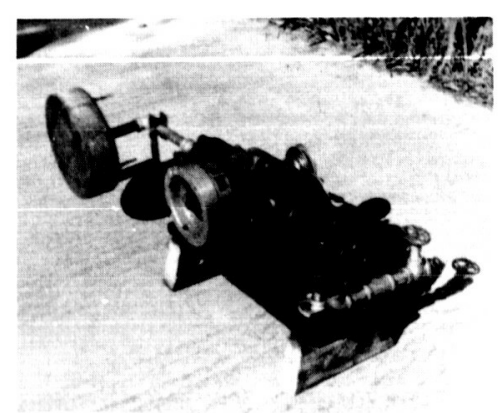

Figure 40. Open-cycle, hot air engine.

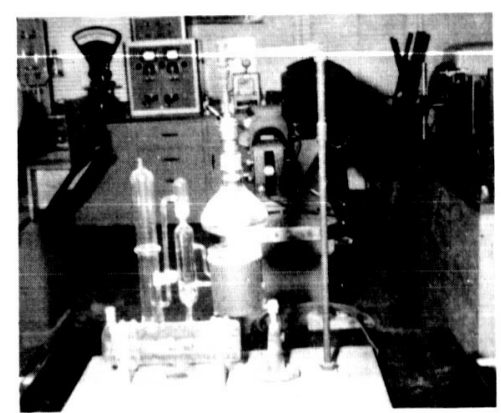

Figure 41. Solar pump. 


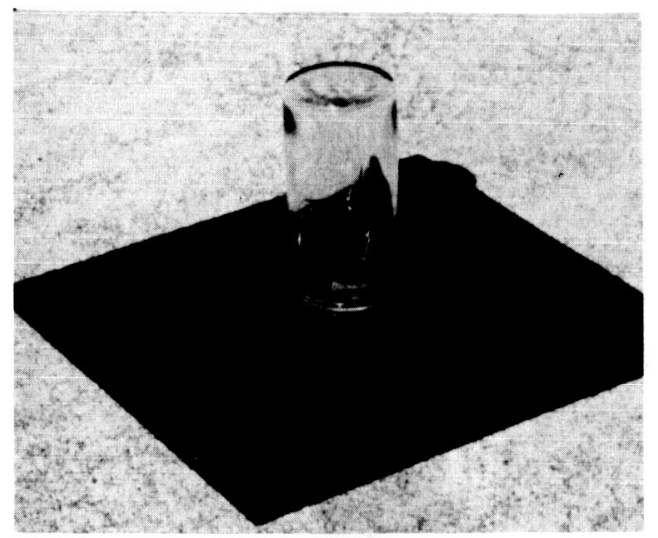

Figure 42. Solar turbine.

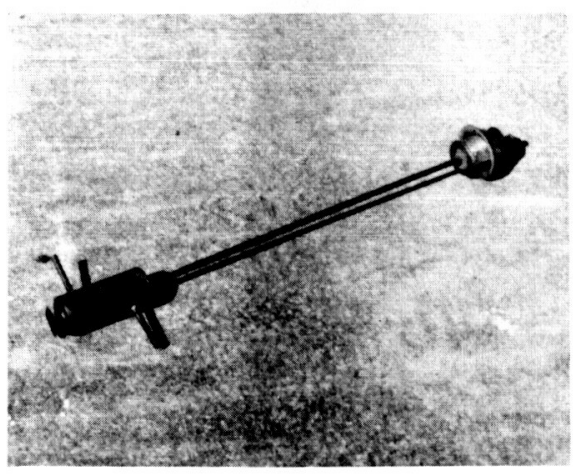

Figure 44. Solar thermo-phase shift reciprocating engine.

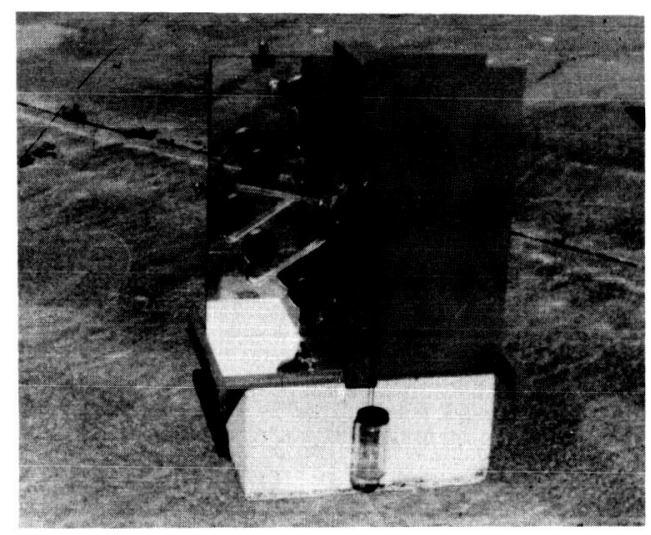

Figure 43. Solar gravity motor.

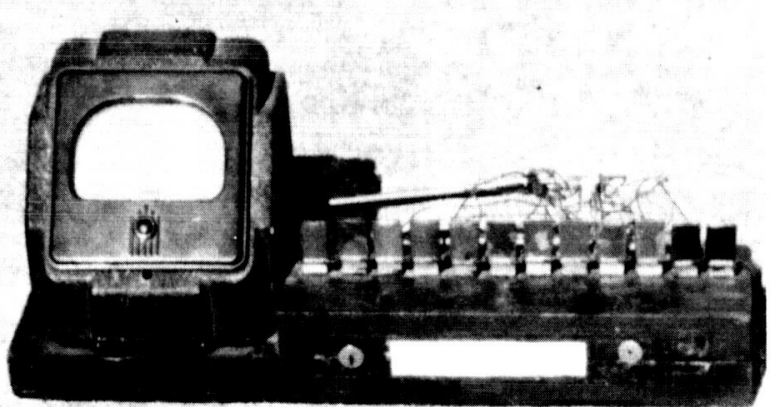

Figure 45. Solar cells.

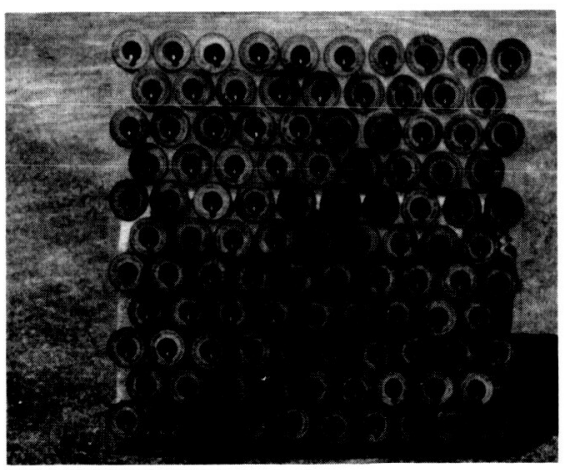

Figure 46. Solar cells. 


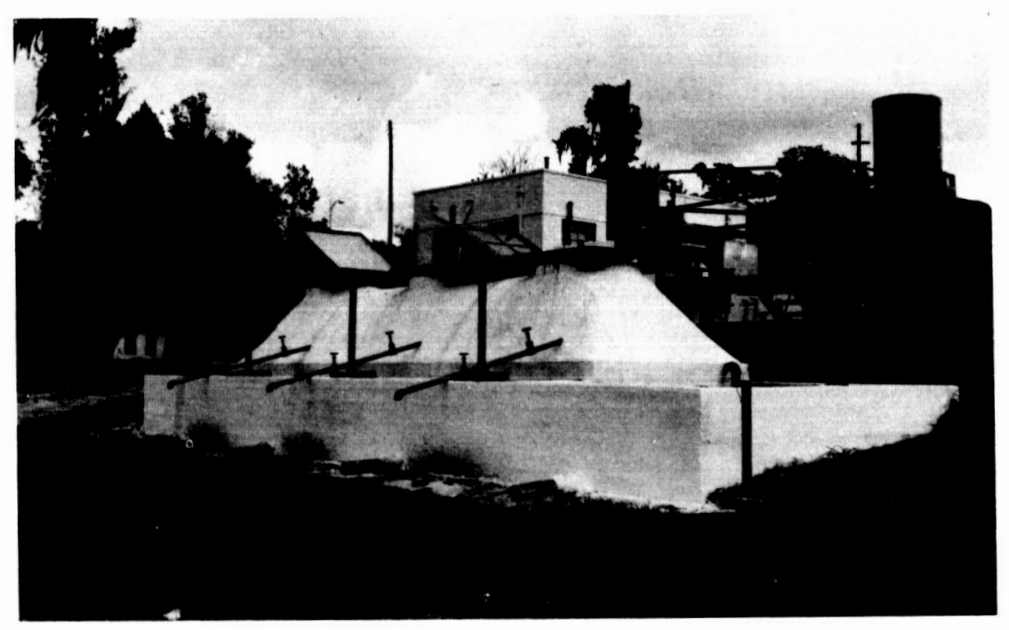

Figure 47. Sewage digesters. 